\title{
Qual a influência do oxigênio em alta concentração na câmara hiperbárica no metabolismo ósseo?
}

João Cassio Cunha (1), Antonio Marcos Realis Rossi (1) e Maicon Ribeiro de Marais (2)

\section{ARTIGO ORIGINAL}

\section{Resumo}

Objetivos: Conhecer as ações do oxigênio em alta concentração na câmara hiperbárica (HC) na expressão de genes relacionados ao metabolismo ósseo em linhagens de células osteoblásticas e osso trabecular humano.

Material e métodos: A expressão diferencial de vários genes relacionados ao metabolismo ósseo (SOST, RUNX2, MMP14, OPG, HIF-1 $\alpha$ e SIRT1) foi analisada em duas linhagens celulares de osteoblastos humanos (Saos e Super-Saos) e em fragmentos de osso trabecular humano submetidos a uma, três ou cinco sessões de $\mathrm{CH}$ (90 minutos, oxigênio a 100\%; 2,3 atmosferas). Um controle que não recebeu $\mathrm{CH}$ foi usado em cada experimento.

Resultados: Não encontramos diferenças significativas após o CH na expressão dos genes estudados, nem nas células nem no osso trabecular. Apenas na linhagem Super-Saos a expressão de OPG após 5 sessões de $\mathrm{CH}$ diminuiu 6 vezes em relação ao grupo controle $\left(2^{-\Delta \mathrm{Ct}}\right.$ de $\left.72 ; \mathrm{p}=0,01\right)$.

Conclusões: $O$ oxigênio em altas concentrações na câmara hiperbárica não parece influenciar a expressão de genes relacionados ao metabolismo ósseo.

Palavras-chave: Oxigênio; Câmara hiperbárica; osso; genes. 


\section{What is the influence of oxygen in high concentration in the hyperbaric chamber on bone metabolism?}

Objectives: To know the actions of oxygen in high concentration in the hyperbaric chamber ( $\mathrm{HC})$ in the expression of genes related to bone metabolism in osteoblastic cell lines and human trabecular bone.

Material and methods: The differential expression of several genes related to bone metabolism (SOST, RUNX2, MMP14, OPG, HIF-1 $\alpha$ and SIRT1) was analyzed in two cell lines of human osteoblasts (Saos and Super-Saos) and in bone fragments human trabecular submitted to one, three or five sessions of $\mathrm{CH}$ (90 minutes, $100 \%$ oxygen; 2.3 atmospheres). A control that did not receive $\mathrm{CH}$ was used in each experiment.

Results: We found no significant differences after $\mathrm{CH}$ in the expression of the studied genes, neither in cells nor in trabecular bone. Only in the Super-Saos strain did OPG expression decrease after $5 \mathrm{CH}$ sessions 6 times compared to the control group ( $-\Delta \mathrm{Ct}$ of $72 ; \mathrm{p}=0.01$ ).

Conclusions: Oxygen in high concentrations in the hyperbaric chamber does not appear to influence the expression of genes related to bone metabolism.

Keywords: Oxygen; Hyperbaric chamber; bone; genes.

Instituição afiliada: 1- Centro de pós-graduação em medicina Ivo Reales, Manaus, Amazonas, Brasil. 2Hospital de urgência e emergência de Manaus.

Dados da publicação: Artigo recebido em 10 de Outubro, revisado em 15 de Outurbro, aceito para publicação em 19 de Outubro e publicado em 29 de Outubro.

DOI: https://doi.org/10.36557/2674-8169.2020v2n11p24-34

@ João Cassio Cunha medcuiman@gmail.com

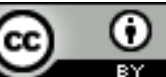

This work is licensed under a Creative Commons Attribution 4.0 International License. 


\section{INTRODUÇÃO}

O oxigênio é necessário para a produção de energia celular e está envolvido em vários processos, como ativação enzimática, sinalização molecular e regulação da expressão gênica ${ }^{1}$. Ainda na angiogênese, a manutenção das células-tronco hematopoéticas e a formação óssea ${ }^{2}$. De fato, mudanças na pressão parcial de oxigênio podem influenciar a função dos osteoblastos e osteoclastos ${ }^{3}$. Na hipóxia, a formação e mineralização óssea diminuem, enquanto a reabsorção aumenta ${ }^{4}{ }^{6}$. Na direção oposta, a hiperóxia pode ter um efeito benéfico no osso. $O$ tratamento com oxigénio a uma concentração elevada em uma câmara hiperbárica $(\mathrm{CH})$ tem-se revelado útil no osteomielite e osteonecrose mandíbula causada por radioterapia ou bisfosfonatos ${ }^{7}{ }^{9}$. $\mathrm{CH}$ acelera a diferenciação osteogénica de células mesenquimatosas e a activação dos osteoclastos diminui.

Neste trabalho, pretendemos analisar as ações do oxigênio em alta concentração no $\mathrm{CH}$ na expressão de genes relacionados ao metabolismo ósseo em linhagens celulares de osteoblastos e osso humano 561314 .

\section{MATERIAIS E MÉTODOS}

\section{Linhas de celular}

Duas linhas de células osteoblásticas Saos-2 e Super-Saos foram usadas. Saos-2, derivado de um osteossarcoma humano. Super-Saos é uma linha gerada em nosso laboratório, derivada da anterior e com alta capacidade de expressar o gene da esclerostina (SOST) ${ }^{15}$. Ambas as linhagens foram cultivadas em frascos T25 com $5 \mathrm{ml}$ de meio de cultura DMEM (meio de cultura Eagle modificado por Dulbeco) mais $1 \% \mathrm{P} / \mathrm{S}$ (penicilinaestreptomicina) e $1 \%$ anfotericina $B$, e foram armazenadas em incubadora a $37^{\circ} \mathrm{C}$ por um semana, mudando o meio de cultura a cada 4 dias para cobrir entre $60-80 \%$ da superfície do frasco. As placas foram introduzidas no HC (Galeazzi, Itália; 100\% oxigênio; 2,4 atmosferas) por 90 minutos por sessão, recebendo uma, três ou cinco sessões consecutivas ( Figura 1) A mesma linhagem celular submetida a condições idênticas de cultura, transporte e manuseio, mas sem sofrer $\mathrm{CH}$, foi usada como grupo controle. 


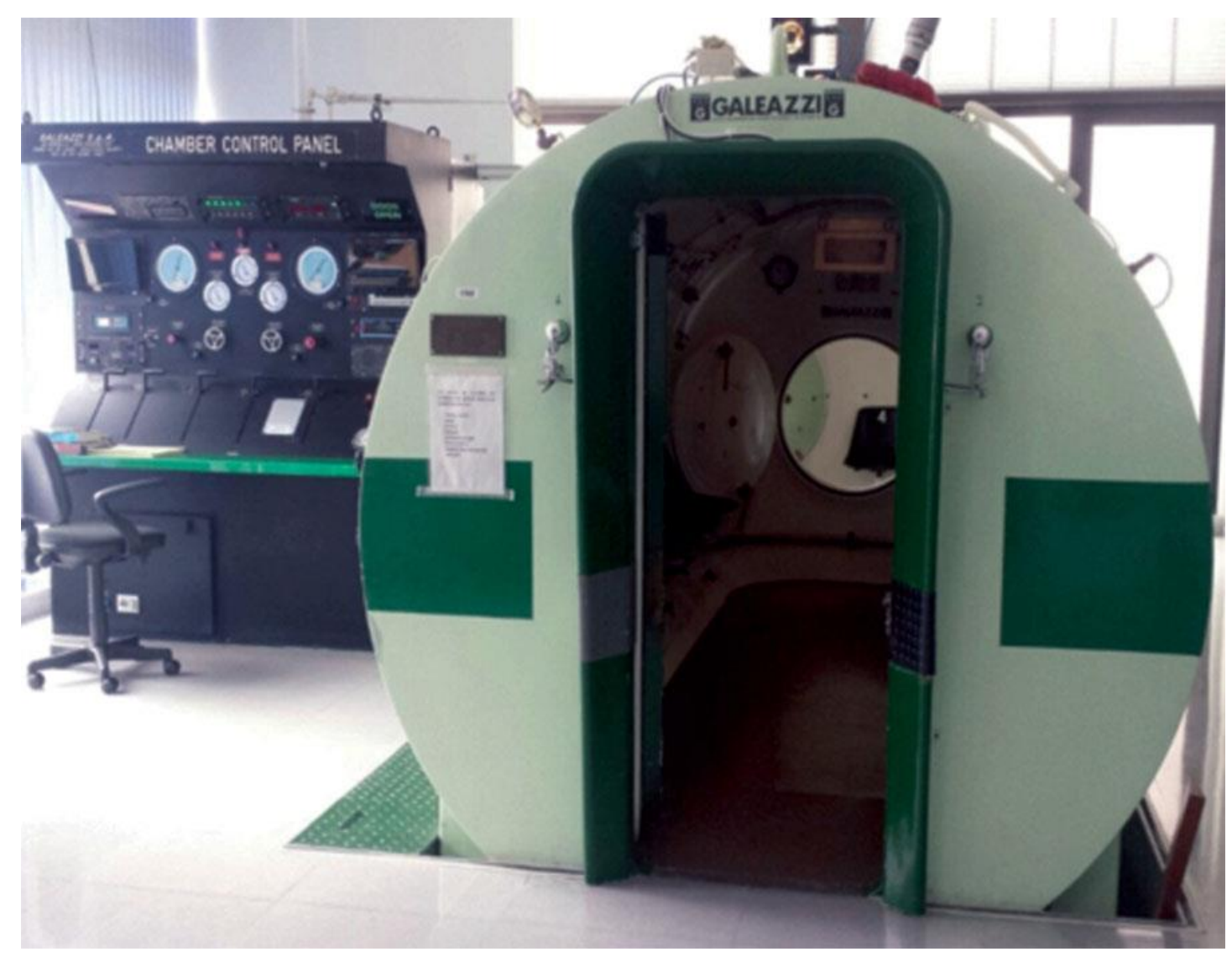

Figura 1. Câmara hiperbárica

\section{Fragmentos ósseos}

Foram utilizados fragmentos de osso trabecular extraídos da cabeça do fêmur de pacientes com cirurgia de substituição do quadril para fratura osteoporótica. Após a extração, os fragmentos ósseos receberam uma única sessão de CH (Galeazzi, Itália; oxigênio 100\%; 2,4 atmosferas) por 90 minutos e, posteriormente, congelados a $-70^{\circ} \mathrm{C}$. Fragmentos ósseos submetidos às mesmas condições de conservação, cultura, transporte e manipulação, mas sem receber $\mathrm{HC}$, foram utilizados como controle. Este experimento foi aprovado pelo Comitê de Ética em Pesquisa Clínica (CEIC) da Cantábria. Todos os pacientes deram seu consentimento informado.

\section{Extração e quantificação de RNA}

24 horas após a última sessão de $\mathrm{CH}$, o RNA foi extraído, tanto nas linhagens celulares quanto nos ossos. No processo de homogeneização em linhagens celulares, as amostras foram lavadas com tampão fosfato salino (PBS) antes do uso do TRIzol ${ }^{\circledR}$. No caso dos fragmentos ósseos, também foi utilizado o TRIzol ${ }^{\circledR}$, bem como homogeneização por 20-30 segundos até que a amostra fosse pulverizada e, posteriormente, centrifugada. Em ambos os casos, as 
recomendações do fabricante foram seguidas e o processo de separação, precipitação e ressuspensão do RNA continuou.

RT-PCR quantitativo (reação em cadeia da polimerase de transcriptase reversa) foi utilizado para detectar a expressão dos genes: SOST (gene da esclerostina), RUNX2 (proteína relacionada ao fator de transcrição 2), MMP14 (metaloproteinase 14), HIF-1 $\alpha$ (fator de indução de hipóxia), SIRT1 (sirtuin1), OPG (osteoprotegerina) e RANKL (ligante ativador do receptor do fator nuclear kappa-B) usando ensaios Taqman e seguindo as instruções do fabricante. Valores de ciclo de limiar ( $\mathrm{Ct}$ ) foram obtidos e os dados foram normalizados para a expressão de GAPDH (gliceraldeído-3-fosfato desidrogenase) e TBP (TATA box-binding protein) usando o método $\Delta \mathrm{Ct}$. Para calcular o nível relativo de mRNA, a fórmula $2^{-\Delta \mathrm{Ct}}$ foi usada, onde $\Delta \mathrm{Ct}$ é a diferença entre a média do $\mathrm{Ct}$ dos genes de normalização e o $\mathrm{Ct}$ do gene de interesse.

\section{Análise estatística}

Testes não paramétricos, o teste de Wilcoxon, foram usados para comparar as médias de dois grupos pareados. Valores de $p<0,05$ foram considerados estatisticamente significativos.

\section{RESULTADOS}

\section{Efeito de CH na expressão de RNA na linha celular Saos-2}

Não houve diferenças na expressão gênica na linha celular após uma, três ou cinco sessões de $\mathrm{CH}$. As diferenças do controle em $2^{-\Delta C t}$ após 5 sessões foram 0,71 para SOST $(p=$ $0,50), 0,89$ para SIRT1 ( $p=0,34), 0,47$ para MMP14 $(p=0,18), 0,43$ para HIF1 $\alpha(p=0,18), 0,79$ para RUNX2 $(p=0,65)$ e 7,91 para OPG $(p=0,40)$ ( Figura 2 ). A expressão de RANKL não foi detectada. 


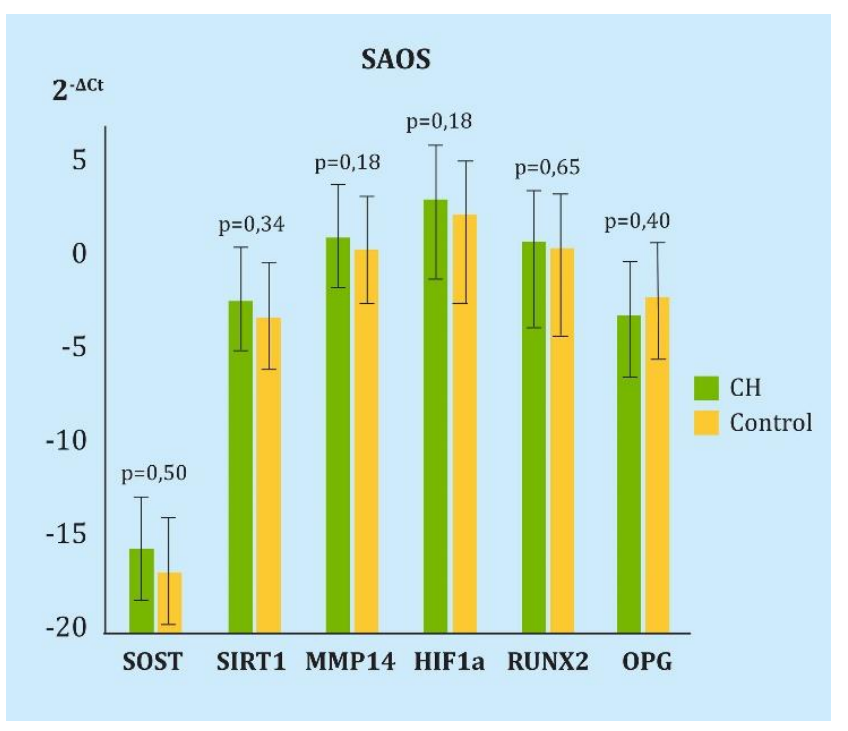

$\mathrm{CH}$ : grupo de células submetido à câmara hiperbárica; SOST: esclerostina; SIRT1: sirtuin1; MMP14: metaloproteinase 14; HIF-1 $\alpha$ : fator $1 \alpha$ indutível por hipóxia; RUNX2: proteína relacionada ao fator de transcrição 2; OPG: osteoprotegerina.

Figura 2. Diferença na expressão dos genes em estudo e housekeeping na linha celular SAOS após 5 sessões de câmara hiperbárica

\section{Efeito do CH na expressão de RNA na linha celular Super-Saos}

Com relação ao controle, descobrimos que a expressão de OPG diminuiu 6 vezes após 5 sessões de $\mathrm{CH}\left(2^{-\Delta \mathrm{Ct}}, 72 \mathrm{p}=0,01\right)$. No restante dos genes não houve diferenças: $2^{-\Delta \mathrm{Ct}}$, de 1,03 para SOST $(p=0,34), 1,46$ para SIRT1 $(p=0,34), 1,77$ para MMP14 $(p=0,18), 1,08$ para HIF1 $\alpha(p=0,18), 1,14$ para RUNX2 $(p=0,18)$ e 1,24 para RANKL $(p=0,31)$ ( Figura 3 ).

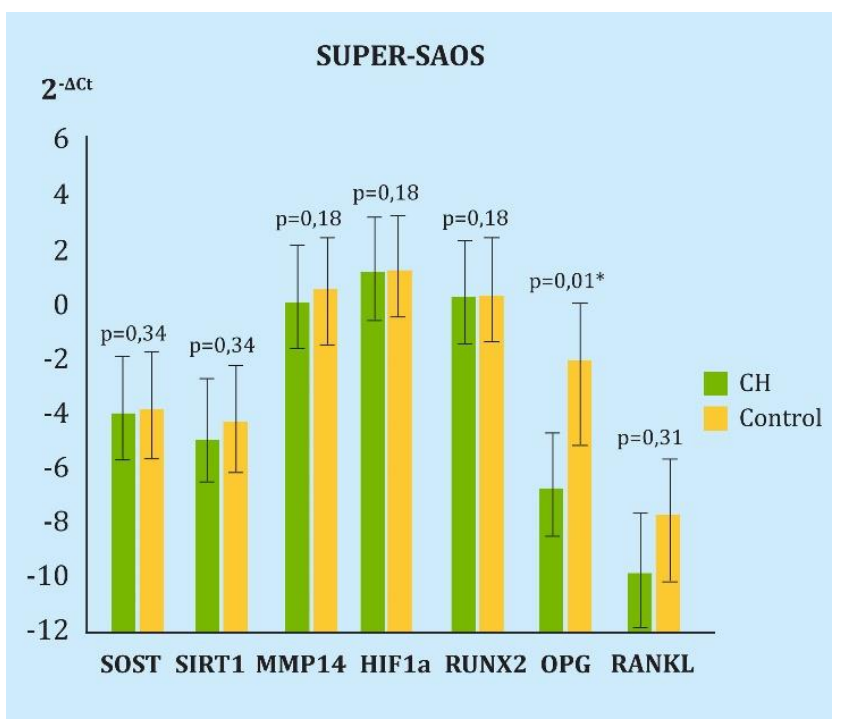

$\mathrm{CH}$ : grupo de células submetido à câmara hiperbárica; SOST: esclerostina; SIRT1: sirtuin1; MMP14: metaloproteinase 14; HIF-1 $\alpha$ : fator $1 \alpha$ indutível por hipóxia; RUNX2: proteína relacionada ao fator de transcrição 2; OPG: osteoprotegerina. 
Figura 3. Diferença na expressão dos genes em estudo e housekeeping na linha celular Super-SAOS após 5 sessões de câmara hiperbárica

\section{Efeito do CH na expressão de RNA no osso trabecular}

Também não houve diferenças na expressão dos genes após $\mathrm{CH}$ no osso, apenas um aumento modesto e não significativo na expressão de SOST com uma alteração de $2^{-\Delta C t}$ de $5,39(p=0,48)$. No restante dos genes, as diferenças foram de 0,92 para MMP14 $(p=0,58)$, 1,28 para HIF1 $\alpha(p=0,81), 0,72$ para RUNX2 $(p=0,24), 1,18$ para SIRT1 $(p=0,42), 1,97$ para $\operatorname{RANKL}(p=0,91)$ e 3,9 para OPG $(p=0,55)$ ( Figura 4 ).

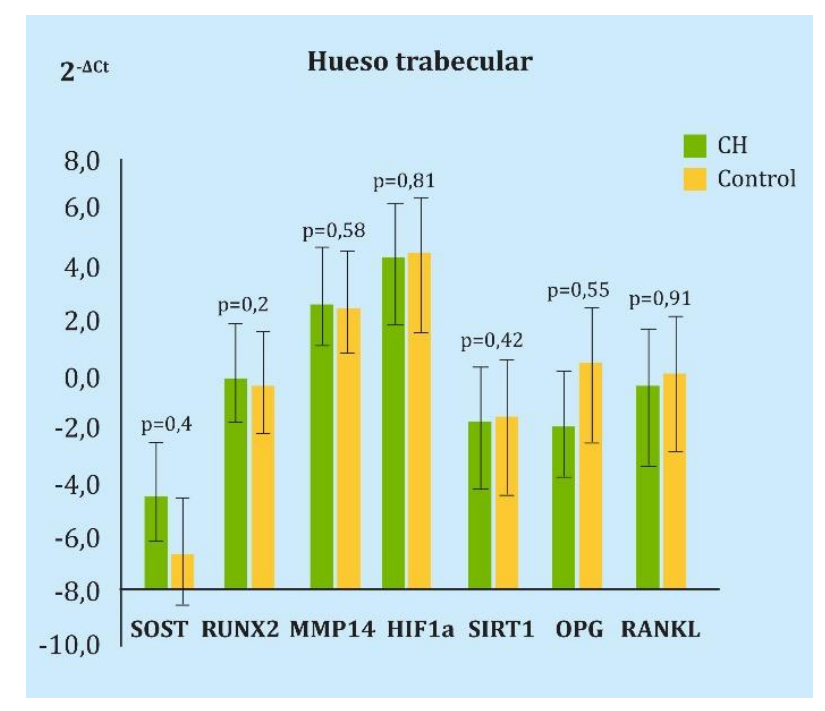

$\mathrm{CH}$ : grupo de células submetido à câmara hiperbárica; SOST: esclerostina; SIRT1: sirtuin1; MMP14: metaloproteinase 14; HIF-1 $\alpha$ : fator $1 \alpha$ indutível por hipóxia; RUNX2: proteína relacionada ao fator de transcrição 2; OPG: osteoprotegerina.

Figura 4. Diferença na expressão dos genes em estudo e housekeeping no osso após uma única sessão da câmara hiperbárica

\section{CONCLUSÃO}

Acredita-se que a hiperóxia possa ser benéfica para o osso por aumentar a proliferação e diferenciação dos osteoblastos ${ }^{16}$. Al Hadi et al. ${ }^{6}$ descreveram um aumento na expressão de colágeno tipo I e mRNA Runx-2 em linhagens celulares de osteoblasto (Saos-2) submetidas a $\mathrm{CH}$ por 14 dias (2,4 ATA, 97\% O 2, $90 \mathrm{~min} / \mathrm{dia})$. O HC também aumentou a proliferação e diferenciação de osteoblastos no osso alveolar humano ${ }^{17}$. A hiperóxia também parece diminuir a reabsorção óssea. O tratamento em $\mathrm{CH}\left(100 \% \mathrm{O}_{2}, 2,4\right.$ ATA) reduziu a expressão de RANK, NFATc1 e Dc-STAMP no soro dos pacientes e também regulou a expressão do fator indutível por hipóxia (HIF-1 $\alpha)^{18}$. Outras ações descritas do oxigênio em alta concentração $\left(\mathrm{O}_{2}\right.$ 100\%, 2,4 ATA) são melhora na angiogênese, aumento da vascularização na crista ilíaca aspirada de camundongos ${ }^{19}$, aumento da proliferação celular ${ }^{20}$ ou aceleração na cicatrização 
de Fraturas expostas de fêmur em animais experimentais ${ }^{21}$. No entanto, a maioria desses estudos foi realizada em modelos animais, com poucos estudos em humanos. Em pacientes com necrose avascular da cabeça femoral, os níveis séricos de OPG aumentaram após HC $(5,61$ $\pm 1,99 \mathrm{pmol} / \mathrm{L}$ basal, 7,90 \pm 1,9 pmol / L após 15 sessões, 8,97 \pm 2 0,07 pmol / L após 30 sessões; $p<0,05)$, sem alterações nos níveis de RANKL ${ }^{22}$. Após HC (2,5 ATA, 100\% $\mathrm{O}_{2}$ por 90 min ( dia), a diferenciação osteogênica das células mesenquimais da medula óssea também melhorou nos pacientes tratados, com regulação positiva em Wnt3a, b-catenina e Runx2 e regulação negativa de GSK-3b, em comparação com aqueles que não o receberam ${ }^{12}$. Esses mesmos autores também descreveram um aumento na proteína morfogenética óssea (BMP2) e Osterix em pacientes tratados ${ }^{12}$.

Em nosso estudo, não descobrimos que a alta concentração de oxigênio no $\mathrm{CH}$ influencia a expressão de diferentes genes relacionados ao metabolismo ósseo (SOST, SIRT1, MMP14, HIF1a, RUNX2, OPG e RNAKL). No entanto, queremos destacar que encontramos uma tendência discreta, não significativa, de aumento da expressão de SOST no osso submetido ao tratamento. Sabemos que a tensão de oxigênio influencia a regulação de SOST e que em hipóxia (tensão de oxigênio a 1\%) os osteoblastos e osteócitos expressam baixos níveis de SOST e esclerostina ${ }^{23}$, talvez isso seja devido a uma menor expressão de prolil-hidroxilase (PHD2 ), uma vez que foi visto que a deleção de PHD2 em osteócitos causa uma menor produção de esclerostina dependente de SIRT1 ${ }^{14}$. Essa via poderia ajudar a entender melhor o mecanismo fisiopatológico pelo qual, e inversamente, um ambiente rico em oxigênio poderia aumentar a expressão de SOST e esclerostina. De fato, nosso grupo encontrou aumento de $25 \%$ nos níveis de esclerostina no soro de 12 pacientes em tratamento no HC. No entanto, outros trabalhos são contraditórios ${ }^{13}$.

Em conclusão, não parece que a hiperóxia no HC influencie a expressão de genes relacionados ao metabolismo ósseo, embora consideremos que mais estudos sejam necessários para aprofundar nosso conhecimento sobre as ações do oxigênio nos ossos.

\section{REFERÊNCIAS}

1. Johnson RW, Sowder ME, Giaccia AJ. Hipóxia e doença óssea metastática. Curr Osteoporos Rep [Internet]. 2017; 15 (4): 231-8. [ Links ]

2. Parmar K, Mauch P, Vergilio JA, Sackstein R, Down JD. Distribuição das células-tronco hematopoéticas na medula óssea de acordo com a hipóxia regional. Proc Natl Acad Sci. 2007; 104 (13): 5431-6. [ Links ]

3. Kusumbe AP, Ramasamy SK, Adams RH. Acoplamento de angiogênese e osteogênese por um subtipo específico de vaso no osso. Natureza. 2014; 507 (7492): 323-8. [ Links ]

4. Arnett TR. Acidose, hipóxia e osso. Arch Biochem Biophys. 2010; 503 (1): 103-9. [ Links ] 
5. Utting JC, Flanagan AM, Brandao-Burch A, Orriss IR, Arnett TR. A hipóxia estimula a formação de osteoclastos no sangue periférico humano. Cell Biochem Funct. 2010; 28 (5): 374-80. [ Links ]

6. Al Hadi H, Smerdon GR, Fox SW. A oxigenoterapia hiperbárica acelera a diferenciação dos osteoblastos e promove a formação óssea. J Dent. 2015; 43 (3): 382-8. [ Links ]

7. Ceponis P, Keilman C, Guerry C, Freiberger JJ. Oxigenoterapia hiperbárica e osteonecrose. Doenças orais. 2017; 23 (2): 141-51. [ Links ]

8. Beth-Tasdogan NH, Mayer B, Hussein H, Zolk O. Intervenções para o gerenciamento da osteonecrose da mandíbula relacionada à medicação. Cochrane Database Syst Rev. 2017; 10: CD012432. [ Links ]

9. Eltorai I, Hart GB, Strauss MB. Osteomielite em lesão medular: Uma revisão e um relatório preliminar sobre o uso de oxigenoterapia hiperbárica. Paraplegia 1984; 22 (1): 17-

24. [ Links ]

10. Al Hadi H, Smerdon GR, Fox SW. A oxigenoterapia hiperbárica suprime a formação de osteoclastos e a reabsorção óssea. J Orthop Res. 2013; 31 [11): 1839-44. [ Links ]

11. Lin SS, Ueng SW, Niu CC, Yuan L, Yang CY, Chen WJ, et al. Efeitos do oxigênio hiperbárico na diferenciação osteogênica de células-tronco mesenquimais. BMC Musculoskelet Disord. 2014; 15 (1): 56. [ Links ]

12. Lin SS, Ueng SWN, Niu CC, Yuan $\amalg$, Yang CY, Chen WJ, et al. O oxigênio hiperbárico promove a diferenciação osteogênica das células do estroma da medula óssea ao regular a sinalização Wnt3a / $\beta$-catenina - um estudo in vitro e in vivo. Stem Cell Res. 2014; 12 [1): 260-74. [ Links ]

13. Fujiwara M., Kubota T., Wang W., Ohata Y, Miura K., Kitaoka T., et al. Indução bemsucedida de esclerostina em fibroblastos de origem humana por 4 fatores de transcrição e sua regulação pelo hormônio da paratireóide, hipóxia e prostaglandina E2. Osso. 2016; 85: 91-8. [ Links ]

14. Stegen S, Stockmans I, Moermans K., Thienpont B., Maxwell PH, Carmeliet P, et al. O sensor de oxigênio osteocítico controla a massa óssea por meio da regulação epigenética da esclerostina. Nat Commun. 2018; 9 (1): 2557. [ Links ]

15. Pérez-Campo FM, Sañudo C, Delgado-Calle J, Arozamena J, Zarrabeitia MT, Riancho JA. Uma linha celular superprodutora de esclerostina derivada da linha celular humana SaOS2: uma nova ferramenta para o estudo dos mecanismos moleculares que direcionam a expressão de esclerostina. Calcif Tissue Int. 2014; 95 (2): 194-9. [ Links ]

16. Chang H, Oh SE, Oh S, Hu KS, Kim S. Avaliação histológica de quatro semanas de defeitos calvários enxertados com terapia de oxigênio hiperbárica adjuvante em ratos. J Periodontal Implant Sci. 2016; 46 (4): 244-53. [ Links ] 
17. Wu D, Malda J, Crawford R, Xiao Y Effects of hyperbaric oxigen on proliferation and differentiation of osteoblasts from human alveolar bone. Connect Tissue Res. 2007; 48 (4): 206-13. [ Links ]

18. Al Hadi H, Smerdon G, Fox SW. A capacidade de reabsorção osteoclástica é suprimida em pacientes recebendo oxigenoterapia hiperbárica. Act Orthop. 2015; 86 (2): 264-9. [ Links ]

19. Grassmann JP, Schneppendahl J, Sager M., Hakimi AR, Herten M., Loegters TT, et al. O efeito do concentrado de medula óssea e da oxigenoterapia hiperbárica no reparo ósseo. J Mater Sci Mater Med. 2015; 26 (1): 5331. [ Links ]

20. Sunkari VG, Lind F, Botusan IR, Kashif A, Liu ZJ, Ylä-Herttuala S, et al. A oxigenoterapia hiperbárica ativa o fator 1 induzível por hipóxia (HIF-1), que contribui para melhorar a cicatrização de feridas em camundongos diabéticos. Regen de reparo de feridas. 2015; 23 (1): 98-103. [ Links ]

21. Kawada S, Wada E, Matsuda R, Ishii N. Hyperbaric hyperoxia acelera a cicatrização de fraturas em camundongos. PLoS One. 2013; 8 (8): e72603. [ Links ]

22. Vezzani G, Quartesan S, Cancellara P, Camporesi E, Mangar D, Bernasek T, et al. A oxigenoterapia hiperbárica modula a OPG / RANKL sérica em pacientes com necrose da cabeça femoral. J Enzyme Inhib Med Chem. 2017; 32 [1): 707-11. [ Links ]

23. Genetos DC, Toupadakis CA, Raheja LF, Wong A, Papanicolaou SE, Fyhrie DP, et al. A hipóxia diminui a expressão de esclerostina e aumenta a sinalização Wnt nos osteoblastos. J Cell Biochem. 2010; 110 (2): 457-67. [ Links ] 